http://jmscr.igmpublication.org/home/

ISSN (e)-2347-176x ISSN (p) 2455-0450

crossref DOI: https://dx.doi.org/10.18535/jmscr/v7i12.117

Journal Of Medical Science And Clinical Research

\title{
Perioperative Difficulties in Previous Caesarean Section and Their On Table Management
}

\author{
Authors \\ Dr Paribhashita Mishra ${ }^{1}$, Dr Rajkishori Dandotiya ${ }^{2}$ \\ ${ }^{1}$ Associate Professor, ${ }^{2}$ Assistant Professor \\ Dept of Obs and Gynaecology, Gajara Raja Medical College, Gwalior, MP, India \\ Corresponding Author \\ Dr Rajkishori Dandotiya
}

\begin{abstract}
Introduction: Incidence of caesarean section is 30\% of all surgeries. In recent times a woman with history of prior caesarean section becomes the most common indication of a repeat caesarean section especially when short interpregnancy interval is present.

Materials and Methods: It is an Prospective observational study done at Kamla Raja Hospital, Gajara Raja Medical College, Gwalior from 2017 to2018 with the aim to study the perioperative difficulties in repeat caesarean section and manage them intraoperatively. Four hundred women with one or more caesarean section irrespective of age or parity were included.

Results: Maximum numbers of cases was between 20-29 years (91.25\%). Out of 300 cases lower segment incision was given in 280 cases (70\%). In 175(43.75\%) cases there was difficulty in entering into abdominal cavity to reach the lower uterine segment due to various types of adhesions present between uterus and surrounding structures.

Discussion: Maximum complications were seen in age 20-29 and commonest complication being adhesions (37.5\%), followed by scar dehiscence (14\%), placenta praevia (3\%), bladder injury (8\%), adherent placenta praevia (1\%) and casarean hysterectomy $(0.5 \%)$.

Conclusion: Cases of caesarean section need to be educated about requirement of antenatal care, contraception, mode of delivery and timely referrals to tertiary centers.
\end{abstract}

\section{Introduction}

Incidence of caesarean section is $30 \%$ of all surgeries $^{(1)}$. In recent times a woman with history of prior caesarean section becomes the most common indication of a repeat caesarean section especially when short interpregnancy interval is present .Key in reducing mortality were:

- Antibiotics and anaesthesia advances

- Asepsis and vertical followed by low transverse caesarean section in 1912
- Suturing techniques and advancement in suture materials.

The mortality rate of caesarean was 20 per 1000,000 (ideal rate should be $15 \%$ of total population.

\section{Methodology}

Observational prospective study carried from 2017 to2018 at Kamla Raja Hospital, Gajara Raja Medical College, Gwalior. The aim of the study 
was to study the perioperative difficulties in repeat caesarean section and manage them intraoperatively.

Inclusion- All women with one or more caesarean section irrespective of age or parity

Exclusion- Other abdominal surgeries.

400 cases were taken after per abdominal examination, signs of rupture uterus and fetal heart rate .Decision of caesarean section was taken after evaluating above condition and per vaginal examination to see dialation, effacement of cervix, maternal condition and those refusing VBAC.

Table: 01 No of previous caesarean section and complication

\begin{tabular}{|l|c|c|c|}
\hline $\begin{array}{l}\text { No of } \\
\text { prev CS }\end{array}$ & $\begin{array}{c}\text { No of } \\
\text { cases }\end{array}$ & $\begin{array}{c}\text { No of } \\
\text { complications }\end{array}$ & $\%$ \\
\hline 1 & 255 & 67 & $37.8 \%$ \\
\hline 2 & 125 & 18 & $21.8 \%$ \\
\hline 3 & 10 & 10 & $100 \%$ \\
\hline
\end{tabular}

Table: 02 Age wise

\begin{tabular}{|l|c|c|}
\hline Age & No of patients & Percentage \\
\hline$<20$ & 2 & $0.5 \%$ \\
\hline $20-29$ & 365 & $91.25 \%$ \\
\hline $30-35$ & 33 & $8.25 \%$ \\
\hline
\end{tabular}

Table: 03 Distribution according to Uterine Incision

\begin{tabular}{|l|c|c|}
\hline Incision & No & $\%$ \\
\hline Lower segment & 380 & $95 \%$ \\
\hline Inverted T & 9 & $2.25 \%$ \\
\hline Classical & 1 & $0.25 \%$ \\
\hline J Shaped & 7 & $1.75 \%$ \\
\hline Upper uterine & 2 & $0.5 \%$ \\
\hline uterine rupture & 1 & $0.25 \%$ \\
\hline
\end{tabular}

Table: 04 Difficulty in Entering Abdominal Cavity and LUS

\begin{tabular}{|l|c|c|}
\hline Adhesions & No. & $\%$ \\
\hline b/w uterus and peritoneum & 75 & $18.75 \%$ \\
\hline b/w omentum and uterus & 58 & $14.5 \%$ \\
\hline b/wbladder and uterus & 23 & $5.75 \%$ \\
\hline $\begin{array}{l}\text { Parietal peritoneum } \\
\text { andomentum }\end{array}$ & 19 & $4.75 \%$ \\
\hline
\end{tabular}

Table: 05 Post Operative Morbidity

\begin{tabular}{|l|c|c|}
\hline & No & $\%$ \\
\hline Anemia & 110 & $27.5 \%$ \\
\hline Wound infection & 65 & $16.25 \%$ \\
\hline Fever & 60 & $15 \%$ \\
\hline UTI & 35 & $8.75 \%$ \\
\hline Secondary haemorrhage & 12 & $3 \%$ \\
\hline Resuturing of wound & 10 & $2.5 \%$ \\
\hline Paralytic ileus & 10 & $2.5 \%$ \\
\hline Relaparotomy & 3 & $0.75 \%$ \\
\hline
\end{tabular}

Table: 05 Indication of Caesarean Section in Previous Pregnancy

\begin{tabular}{|l|c|c|}
\hline & No & $\%$ \\
\hline CPD & 115 & $28.75 \%$ \\
\hline Fetal distress & 76 & $19 \%$ \\
\hline Eclampsia/GHTN & 44 & $11 \%$ \\
\hline Postdatism with NPOL & 42 & $10.5 \%$ \\
\hline APH & 27 & $6.75 \%$ \\
\hline Breech & 22 & $5.5 \%$ \\
\hline Failed induction & 20 & $5 \%$ \\
\hline Transverse & 11 & $2.75 \%$ \\
\hline Oligohydroamnios & 20 & $5 \%$ \\
\hline Short interval pregnancy & 23 & $5.75 \%$ \\
\hline
\end{tabular}

\section{Discussion}

Age groups of patients for caesarean section were between 18-35years with most common 20-29 years. Maximum complications were seen in age 20-29 and commonest complication being adhesions $(37.5 \%)$, followed by scar dehiscence $(14 \%)$, placenta praevia (3\%), bladder injury $(8 \%)$, adherent placenta praevia (1\%) and casarean hysterectomy $(0.5 \%)$

In our study patients who had repeat caesarean section their incidence was $37.8 \%$.Study by Pushpa showed rate of caesarean section being $36.5 \%$ complication that were found peroperatively showed an increament with age which was similar to study by Jilam ${ }^{(4)}$ This was in contrast to study by Lisa $\mathbf{J}$ and Naye RL which suggested maximum women with complication being 30-35 years due to dysfunction in vascular endothelium which seemed to increase with age ${ }^{(4)}$ In our study commonest complication was adhesions $43 \%$ which was similar to study by Lyell which had $45 \%{ }^{(5)}$. Adhesion between peritoneum and uterus was maximum followed by that between omentum and uterus which was similar to study by Wills and Nahar ${ }^{(7)}$ in the above cases adhesionolysis was done. Adhesion can be reduced by putting cellulose seprafilms adhesion barriers (sodium hyaluronase and carboxymethylcellulose) but large trials are going on. Adhesions are generally formed due to inflammations and infections. In our study patients with history of previous 3 caesarean sections had most amount of adhesion (100\%) followed by haemorrhage complications like extension, adhesion, placenta 
praevia and rupture uterus which were seen in patients with previous 2 caesarean sections .This was relatable to study by Farkund ${ }^{(3)}$ which showed thinned segment $16 \%$, rupture uterus $1 \%$, adhesions $35 \%$ and $2 \%$ increase rate of placental invasion .

Milosevic et al found $14.4 \%$ placenta praevia after 3 caesarean section ,5.4\% rate after 2 caesarean section and $1.86 \%$ after 1 caesarean section ${ }^{(9)}$. Scar dehiscence and rupture was increased with increase number of caesarean sections. This was in coherence with study by Jatoi $\mathrm{N}$ which had 5\% scar dehiscence in previous 3 caesarean section $4 \%$ in previous 2 caesarean sections ${ }^{(10)}$. In our study uterine rupture was seen in 8 patients out of which 6 were repaired and two patient underwent caesarean hysterectomy .This study was comparable with Ramakrishna $\mathrm{Rao}^{(8)}$ which showed $2.9 \%$ rupture rate .In study by Shella's $0.5 \%$ required caesarean hysterectomy ${ }^{(10)}$.

In our study $8 \%$ cases showed bladder injury which was tackled by suturing with vicryl in 2 layers followed by retrograde filling and catheterization for 14 days. Study by Nahar showed $6 \%{ }^{(7)}$

In present study $12.6 \%$ haemorrhage rate was present owing to abnormal placentation, atonic uterus and adhesions. Incidence was more than that reported by Wuttikonsammit et al which was $6 \% .^{(11)}$. It was treated by bilateral uterine and ovarian artery ligation. In others uterotonics, intrauterine packing and Bakri BaIlon or intrauterine tamponade was instilled. Blood transfusion was done in anaemic patients or in those who required so. In our study commonest indication of repeat caesarean section was fetal distress followed by CPD .Repeat caesarean was associated with various maternal complication as compared to first caesarean section. ${ }^{(12,13)}$

\section{Conclusion}

Cases of caesarean section need to be educated about requirement of antenatal care, contraception, mode of delivery and timely referrals to tertiary centers.

\section{References}

1. Panday GV. Second Stage caesarean section at a tertiary centre in South Africa, Journal of Maternal -Fetal Neonat medic.2010;23(10)1151-1155185-93.

2. Pai, Madhukar (2000) "Medical Interventions; Caesarean Sections as a case Study. Economic and Political Weekly 35 (31) :2755-61

3. Intraoperative Complications Encountered in Patients with repeat caesarean section Farkhundah and Khursheed, Pushpa Sirichand Nasreen JLUMHS. Jan -April1 2009; vol :08no .01 Jatoi

4. Jillani, Shaikh F, Siddiqui $\mathrm{S}$ and Siddhiqui M (2010).Repeated caesarean sections; A Risk factor for rising rate of placenta praevia. Gynaecology \& Obstetrics ,16 (3),409-412

5. Darmas B. Use of barrier products in prevention of adhesion formation after surgery .J Wound Care 2008 ; 17:4058,411

6. Ojo Va, Okwerekwu FO.A critical analysis of rates and indication of caesarean section in a developing country. Asia -Oceanic. J Obstet Gynaecol.1988;14:

7. Nahar K, Akhter, Chowdhary SB outcome of pregnancy with history of previous caesarean section. The ORION Medical Journal 2008 Sep; 31:588-590.

8. Ramkrishnarao M.A ,Popat G.H, Eknath B.P, Panditrao S.A. Intraoperative difficulties in repeat cesarean section-A study of 287 cases .J Obstet Gynecol India . 2008 ;58507-510

9. Milosevic et al. Placental complication after a previous caesarean section .Med Pregl 2009 ; 62 :212-14

10. Shellhaas C S, Gilbert S, Landon MB et al. The frequency and complication rates of complication rates of hysterectomy accompanying cesarean delivery . Obstetgynecol $2009 ; 114$ : 224-9. 
11. Wuttikonsammit P, Sukcharoen N.J Med Assoc Thai 2009 Oct; 89 Suppl4: Suppl 4:S81-6

12. Kaplanoglu M, Bulbul $M$ et al .effect of multiple repeat caesarean sections on maternal morbidity : Data from South East Turkey :Mustafa Kaplanoglu Med Sci Monit .2015;21:1447-53

13. Leung AS, Leung EK, Paul RH. Uterine rupture after previous caesarean delivery; maternal and fetal consequences. Is $\mathbf{J}$ Obstet Gynecol.1993; 69:945-50. 